\title{
TITLE: Heterogeneity in COVID-19 Pandemic-Induced Lifestyle Stressors and Predicts Future Mental Health in Adults and Children in the US and UK
}

Authors: Aki Nikolaidis $\mathrm{PhD}^{1}$, Jacob DeRosa ${ }^{1}$, Mirelle Kass ${ }^{1}$, Irene Droney ${ }^{1}$, Lindsay Alexander $\mathrm{MPH}^{1}$, Adriana Di Martino $\mathrm{MD}^{1}$, Evelyn Bromet $\mathrm{PhD}^{2}$, Kathleen Merikangas $\mathrm{PhD}^{3}$, Michael Peter Milham MD PhD*1, Diana Paksarian MPH PhD*3

1- Child Mind Institute

2- Stony Brook University

3- National Institute of Mental Health

*Equal Contribution

Word Count: 3146

Corresponding Author:

Aki Nikolaidis

Email: g.aki.nikolaidis@gmail.com.

Twitter@AkiNikolaidis

\section{Abstract:}

Identifying predictors of mental health symptoms after the initial phase of the pandemic may inform the development of targeted interventions to reduce its negative long-term mental health consequences. In the current study, we aimed to simultaneously evaluate the prospective influence of life change stress, personal COVID-19 impact, prior mental health, worry about COVID-19, state-level indicators of pandemic threat, and socio-demographic factors on mood and anxiety symptoms in November 2020 among adults and children in the US and UK. We used a longitudinal cohort study using the Coronavirus Health Impact Survey (CRISIS) collected at 3 time points: an initial assessment in April 2020 ("April"), a reassessment 3 weeks later ("May"), and a 7-month follow-up in November 2020 ("November"). Online surveys were collected in the United States and United Kingdom by Prolific Academic, a survey recruitment service, with a final sample of 859 Adults and 780 children (collected via parent report). We found subtypes of pandemic-related life change stress in social and economic domains derived through Louvain Community Detection. We assessed recalled mood and perceived mental health prior to the pandemic; worries about COVID-19; personal and family impacts of COVID-19; and socio-demographic characteristics. Levels of mood symptoms in November 2020 measured with the circumplex model of affect. We found 3 life change stress subtypes among adults and children: Lower Social/Lower Economic (adults and children), Higher Social/Higher Economic (adults and children), Lower Social/Higher Economic (adults), and Intermediate Social/Lower Economic (children). Overall, mood symptoms decreased between April and November 2020, but shifting from lower to higher-stress subtypes between time points was associated with increasing symptoms. For both adults and children, the most informative predictors of mood symptoms in November identified by conditional random forest models were prior mood and perceived mental health, worries about COVID, and sources of life change. The relative importance of these predictors was the most prominent difference in findings between adults and children, with lifestyle changes stress regarding friendships being more predictive of mood outcomes than worries about COVID in children. In the US, objective state-level indicators of COVID-19 threat were less predictive of November mood than these other predictors. We found that in addition to the well-established influences of prior mood and worry, heterogeneous subtypes of pandemic-related stress were differentially associated with 
medRxiv preprint doi: https://doi.org/10.1101/2021.08.10.21261860; this version posted August 11, 2021. The copyright holder for this preprint (which was not certified by peer review) is the author/funder, who has granted medRxiv a license to display the preprint in perpetuity.

All rights reserved. No reuse allowed without permission.

mood after the initial phase of the pandemic. Greater research on diverse patterns of pandemic experience may elucidate modifiable targets for treatment and prevention.

\section{Introduction}

As the COVID-19 pandemic has led to worldwide illness, death, and disruptions in daily life, its effects on emotional well-being have become a public health priority. ${ }^{1}$ Overall, studies have demonstrated high levels of anxiety and related conditions in samples of adults, ${ }^{1,2}$ with fewer investigations in children and adolescents. ${ }^{3}$ Most studies have been cross-sectional, and many have focused on at risk subgroups (e.g., healthcare and essential workers). ${ }^{4}$ Longitudinal studies of general population samples have found that mental health problems initially increased compared to pre-pandemic levels, ${ }^{5-7}$ followed by a decrease as the pandemic continued. ${ }^{8-10}$ This is consistent with prior research on population mental health responses to disaster, which has shown that while transient increases in symptomatology are common, long-lasting problems are rare. ${ }^{11}$ Longitudinal studies that identify predictors of poor mental health versus resilience after the initial phase of the pandemic could help to inform the development of targeted interventions to reduce long-term mental health consequences.

Prior disaster mental health research has consistently found that pre-disaster mental health and the degree of fear and worry during a disaster are primary determinants of mental health outcomes. ${ }^{12}$ Mental health responses to disaster are also worse among those who are directly and severely impacted, and vary by sociodemographic characteristics such as younger age, gender, lower income, and minority race/ethnicity. ${ }^{13}$ Consistent with these findings, initial work by our team and others highlighted prior mental health and the degree of worry about COVID-19 as key predictors of mood in the initial months of the COVID-19 pandemic. ${ }^{2,14}$ Along with others, our prior work also highlighted the importance of the widespread changes in daily life and accompanying stressors induced by the pandemic for mental health. ${ }^{9,15-20}$ Together these prior findings underscore the multifactorial influences of the pandemic among families and individuals. A greater understanding of the long-term role of pandemic-related life change stress, in relation to other risk factors for poor mental health, is needed in order to understand potential avenues for intervention.

The goal of the current study was to extend our previous findings by using a longitudinal design to characterize the role of life change stress in shaping mood after the initial phase of the COVID-19 pandemic. After an initial assessment in April 2020 ("April"), we reassessed participants three weeks later ("May") to capture rapid changes during the beginning of the pandemic, and then conducted a 7-month follow-up in November 2020 ("November") among our cross-national sample of adults and children (assessed via self and parent report, respectively) in the US and UK. Our aims were to: 1) Define subtypes of life change stress at 3 weeks and their associations with mood and other correlates. 2) Assess the stability of subtype membership across time points, and how subtype transitions were associated with changes in mood and worries about COVID-19. 3) Identify the importance of life change stress subtypes in predicting mood at follow up, while considering other factors including demographics, recalled prior mood and mental health, worries about COVID-19, personal and family pandemic impact, and objective state-level indicators of pandemic threat. To our knowledge, this is the first longitudinal study to simultaneously investigate the roles of life change stresses, personal COVID-19 impact, prior mental health, worry about COVID-19, state-level indicators, and socio-demographic factors in levels of mood among adults and children in multiple countries.

\section{Methods}

\subsection{Samples}


Data were collected through Prolific Academic (PA; https://www.prolific.ac/), an online crowdsourced survey recruitment service (Table 1). Participants who signed up to join the PA participant pool received monetary compensation for their time. PA offers samples that broadly reflect the population distributions of age, sex, and race in the US and UK; participants have been shown to be more diverse and provide higher quality data than similar data collection platforms. ${ }^{21}$ In March 2020 we requested four samples of 1,500 participants from the US and UK, both adult self-report and parent report. Portions of the sample were targeted at regions that were more severely impacted by COVID-19 in late March 2020 (New York, California, London, and Manchester). For the child (parent report) sample, users were screened based on having a child between 5 and 18 years old and were asked to report on their oldest child in that age range; reports received for children over age 25 were excluded. No additional exclusion criteria were given to PA.

Three waves of data were collected in 2020: at baseline (April $7^{\text {th }}-17^{\text {th }}$ ), 3 weeks (April $24^{\text {th }}-$ May $4^{\text {th }}$ ), and 7 month follow up (October $31^{\text {st }}$-November $23^{\text {rd }}$ ). For the present analyses we excluded participants with uncompleted forms and incomplete information for subtyping (described below). Final analytic sample sizes were: 3,259 in April (1,793 adults and 1,466 parents), 2,553 at 3 weeks (1,380 adults and 1,173 parents), and 1,639 in November (859 adults and 780 parents) (see eTable 1).

Exemption from IRB oversight was approved by the Advarra Institutional Review Board. PA participants were required to agree to PA's Terms of Service notification (https://prolific.ac/assets/docs/Participant Terms.pdf) to complete surveys. Per the IRB exemption, no additional informed consent was required. Comparisons between the demographics of the included sample and both the drop out and Census for US and UK are included in the supplement (eTable 2, eTable 3).

\subsection{Measures}

The Coronavirus Health Impact Survey (www.crisissurvey.org) was administered online via REDCap software at all 3 time points. Abbreviated baseline versions of CRISIS v0.3 were administered in April and follow-up versions of CRISIS v0.3 were administered in May. The CRISIS v0.3 baseline forms were revised and expanded for the November follow-up (available by request).

\subsubsection{Mood}

Ten items from the circumplex model of affect ${ }^{22,23}$ (see Supplement) rated on a 5-point scale were included to measure mood. Prior mood was assessed at baseline by asking participants to recall the 3 months prior to the pandemic. Mood over the past 2 weeks ("Current mood") was included from the May and November time points. Based on excellent unidimensional fit (see eTable 4), items were averaged to generate a total score (range: 1 to 5), with higher scores indicating worse mood. Unadjusted associations with mood are included in the supplement (eTable 5, eTable 6).

\subsubsection{Predictors}

Participant characteristics: Age, sex, self- or parent-rated mental and physical health, urbanicity, informant education, and employment (adults only) were reported on the CRISIS in April. Race was reported to PA and combined with CRISIS information on Hispanic ethnicity to generate the following categories: Hispanic, nonHispanic White, non-Hispanic Black, Asian, and Other race/ethnicity. For children, parent race was used as a proxy for child race. Perceived mental health prior to the pandemic, and physical health during the pandemic, were rated on 5-point scales from "excellent" to "poor."

Personal COVID-19 impact: Perceived exposure to SARS-CoV-2, COVID-19 symptoms, family member diagnosis of COVID-19, and impacts on family members such as hospitalization, quarantine, and job loss 
medRxiv preprint doi: https://doi.org/10.1101/2021.08.10.21261860; this version posted August 11, 2021. The copyright holder for this preprint (which was not certified by peer review) is the author/funder, who has granted medRxiv a license to display the preprint in perpetuity.

All rights reserved. No reuse allowed without permission.

because of COVID-19 were reported on the CRISIS in May with respect to the past 2 weeks. In April, participants reported whether they or a household member were an essential worker.

COVID-19 Worries in the past two weeks: In May, participants reported on a five-point Likert scale how worried they have been during the past two weeks about infection, friends and family being infected, and possible impacts on physical and mental health, as well as time spent reading or talking about COVID-19 and hope that the pandemic will end soon. Based on psychometric analyses (described in supplement), these were averaged to generate a total score (range: 1 to 5; hereafter referred to as "COVID-19 Worries").

Life Changes due to the pandemic in the past two weeks: Downstream and subjective impacts of structural changes, such as changes in social contacts, effects on family relationships, changes in living situation, food insecurity, and stressors associated with these changes were reported on the CRISIS (14 items; see Supplement). Life change stress subtypes were derived independently at all 3 timepoints based on these items (described below).

Objective Government Response Tracker (OxCGRT) Indices: Following the model of Vibert et al., (in prep), state-level indices from OxCGRT ${ }^{24}$ were used to indicate objective levels of COVID-19 threat in each US participant's state. Specifically, we included: Containment and Health Index (lockdown restrictions and closures related to COVID-19), Economic Support Index (economic relief for households provided by the government), Confirmed Cases by state per 1,000,000 residents, and Confirmed Deaths by state per 1,000,000 residents (see Supplemental Methods). These indices covered the time period: January 1st, 2020 to March 19th, 2021. Average values of each index were calculated from April 1st to May 31st. Regionally specific containment data were not available for the UK, and so our analyses using containment included only US data.

\subsection{Analysis}

Community Detection Based Subtyping (Aims 1 \& 2): Life change stress subtypes were derived using Louvain community detection (Aim 1; LCD; Figure 1; eFigure 1; see supplemental methods), enhanced through bootstrap aggregation (i.e., bagging), as in our prior study. ${ }^{20}$ Structural similarity across samples and timepoints was confirmed using Pearson's correlation. LCD is a clustering technique that selects clusters to maximize within-cluster coherence and between-cluster segregation. Subtype differences between individual items are described in the supplement (eTable 7). We compared demographic characteristics and COVID-19 impact indicators across May subtypes using one-way ANOVA (Table 2; eTable 8). We also estimated mean mood and COVID-19 Worries scores according to patterns of change in subtype membership across the 3 timepoints and used t-tests to test mean differences (Aim 2; Figure 2).

Conditional Random Forest (Aim 3): Finally, we used conditional random forest (CRF) to predict mood in November based on prior mood and perceived mental and physical health, COVID-19 worries factor scores, May life change stress subtype, OxCGRT indices, socio-demographic characteristics, and personal and family COVID-19 impact. Random forest (RF) is a robust predictive machine learning technique known for its ability to handle dependencies and interactions between predictor variables (See Supplemental Methods). ${ }^{26,27} \mathrm{CRF}$ overcomes some limitations of traditional RF and estimates how much each variable contributes to overall model accuracy, conditioned on other included variables. ${ }^{28}$ We built 3 sets of CRF models: a base model including all predictors described above, using life change stress subtypes; a second model which replaced life change stress subtypes with their constituent items; and a third model in the US sample alone which added the OxCGRT indices. 
medRxiv preprint doi: https://doi.org/10.1101/2021.08.10.21261860; this version posted August 11, 2021. The copyright holder for this preprint (which was not certified by peer review) is the author/funder, who has granted medRxiv a license to display the preprint in perpetuity.

All rights reserved. No reuse allowed without permission.

Because our prior study demonstrated highly reproducible findings across the US and UK, and to maximize power for prediction modeling, analyses were conducted combining the US and UK samples. The proportion of missing data in the analytic sample was less than $2 \%$ for all variables and missing data were handled via model-wise deletion.

\section{Results}

\subsection{Sample Characteristics}

Table 1 shows demographic characteristics and COVID-19 impact indicators for the November 2020 sample, along with means and standard deviations of November mood scores. The majority of adults were females $(57.6 \%)$, white $(75.1 \%)$, and aged $30-39(24.7 \%)$, while the majority of children were males $(53.6 \%)$, white (81.5\%), and aged 6-13 years (60.3\%). Overall, mood symptom and COVID-19 Worries levels decreased between the April and November both adults (mood: -0.13 ; $p<.0001$; COVID-19 Worries: $-0.35 ; p<.0001$ ) and children (mood: -0.17; $\mathrm{p}<.0001$; COVID-19 Worries: $-0.16 ; \mathrm{p}<.0001$ ). Differences in November mood by participant characteristics are displayed in Table 1. Mean COVID-19 Worries and prior mood scores by demographics and COVID-19 impact indicators are presented in eTables 5 and 6.

\subsection{Life change stress subtypes (Aim 1)}

Life change subtypes derived from the 3-week time point (Figure 1) were named based on relative ratings of social/interpersonal and economic stressors (See eTable 7 and supplemental results). Adult subtypes were: Lower Social/Lower Economic stress (purple; 1), Higher Social/Higher Economic stress (blue; 2), and Lower Social/Higher Economic stress (orange; 3). Among children, subtypes were: Lower Social/Lower Economic (purple; 1), Higher Social/Higher Economic (blue; 2), and Intermediate Social/Lower Economic stress subtype (orange; 3).

\subsection{Longitudinal Subtype Change (Aim 2)}

Figure 2 shows the stability of, and change in, subtype membership across time points, with accompanying mean scores for COVID-19 Worries and mood. Most participants stayed in the same subtype across time points. Specifically, 805/1,380 adults and 747/1,173 children remained stable between April and May, and 492/859 adults and 396/780 children remained stable between May and November. Subtype 3 (Lower Social/Higher Economic for adults and Intermediate Social/Lower Economic for children) appeared the least stable. We saw an overall trend of either decrease or no change in COVID-19 Worries and mood across timepoints and subtypes for both adults and children. The only significant increase among adults was in mood for those who moved from the Lower Social/Lower Economic subtype in May to the Higher Social/Higher Economic subtype in November (estimate $=0.14, \mathrm{p}<.05$ ). More increases were seen among children. Children who changed from Lower Social/Lower Economic to Higher Social/Higher Economic showed increases in COVID Worries (April-May only; estimate $=0.14, p<.05$ ) and mood (April-May: estimate=0.32, $p<.001$; MayNovember: estimate $=0.25, p<.01)$. Children who moved from Intermediate Social/Lower Economic to Higher Social/Higher Economic showed increases in mood symptoms across both transitions (April-May: estimate $=0.16, \mathrm{p}<.01$; May-November: estimate $=0.17, \mathrm{p}<.05)$.

\subsection{Predicting November Mood (Aim 3)}

Conditional random forests including participant characteristics, COVID-19 impact indicators, prior mood and mental health, COVID-19 worries, and life change subtypes predicted substantial variation in November mood (Figure 3; Adult $\mathrm{R}^{2}=59.4 \%$; Child $\mathrm{R}^{2}=47.8 \%$ ). The most important predictors were prior mood, COVID-19 Worries, prior perceived mental health, and life change subtype for adults and children. While COVID-19 Worries was the second most informative predictor for adults, life change subtypes were the second most 
informative for children. When life change stress was included as individual items, social/interpersonal stress items showed the highest conditional variable importance for both adults and children, and the variance explained increased (Figure 3; Adult $R^{2}+5.4 \%$; Child $R^{2}+8.6 \%$ ). For the US samples of adults and children, adding indicators of US state-level COVID-19 threat from OxCGRT (eFigure 2) modestly increased variance explained, but these variables exhibited lower conditional importance (Adult $R^{2}+3.1 \%$; Child $R^{2}+1.1 \%$ ) relative to other variables.

\section{Discussion}

In a longitudinal study covering the beginning of the COVID-19 pandemic and a six month follow-up between April and November 2020, we found that prior mood, worry about COVID-19, and profiles of pandemic-induced life change stress were the most important predictors of mood symptom levels in November 2020. The importance of prior mood and worry about COVID-19 is supported by extensive prior studies of mental health during the pandemic, ${ }^{15,17,29,30}$ as well as studies following other large scale traumatic events (i.e., natural disasters, terrorist attacks, nuclear reactor meltdowns). ${ }^{12,31-33}$ Of note, the relative importance of these three predictors was the most prominent difference in findings between adults and children, with lifestyle changes stress (particularly that related to friendships) being more predictive of mood outcomes than worries about COVID-19 in children. Country did not emerge as an important predictor of later mood, implying similarity of predictors across sites. The importance of the life change stress subtypes underscores the heterogeneity in the effects of the pandemic on people's lives.

In the current study, patterns of life change stress were highly reproducible across samples and over time. They largely captured individual variation in secondary effects of the pandemic beyond medical illness, such as changes in social relationships and financial security. Their importance is consistent with other studies of the COVID-19 pandemic, which have found associations of social distancing, stay-at-home orders, and financial strain with mental health. ${ }^{34-36}$ Our analysis of stability and switching life change stress subtypes indicated that for most groups, mood symptoms decreased between time points. This is consistent with other COVID-19 research showing that mental health symptoms rose at the start of the pandemic and subsequently declined. ${ }^{9,16}$ Higher mood levels in November may be an indicator of risk for prolonged mental health problems following the pandemic, although this needs to be confirmed with additional follow-up. Groups who deviated from the decreasing pattern were those who changed into a high-stress subtype between study waves, further demonstrating the importance of variation in life change stress as a contributor to mental health. The greater importance of life change stress subtypes over objective state-level indicators of pandemic threat may be because they are more proximally tied to mental health.

Although we cannot infer causal relationships, our longitudinal results may help to inform the targeting of intervention strategies and anticipate health services needs during future crises. ${ }^{38}$ Individuals with higher levels of symptoms prior to the pandemic are at risk of continued poor mental health during the pandemic, and should be regarded as a vulnerable subgroup. ${ }^{15,17,39}$ Research from prior disasters and the current pandemic has demonstrated the importance of reliable information in shaping people's degree of fear and worry about an event. $^{40,41}$ Therefore, national-level efforts to provide more high-quality information about COVID-19 and increase trust in legitimate information sources may help to decrease mood-anxiety symptoms among the general public. Economic stressors captured in the life change stress profiles may be addressed through policy interventions that decrease housing instability, food insecurity, and economic hardship. ${ }^{42,43}$ Sources of social and interpersonal stress may vary widely and therefore be more difficult to intervene on from a population level. However, strategies that may be useful include the provision of psychoeducational and coping resources, ${ }^{44}$ implementation of programs to reduce domestic and intimate partner violence and provision of 
medRxiv preprint doi: https://doi.org/10.1101/2021.08.10.21261860; this version posted August 11, 2021. The copyright holder for this preprint (which was not certified by peer review) is the author/funder, who has granted medRxiv a license to display the preprint in perpetuity. All rights reserved. No reuse allowed without permission.

resources for those affected, ${ }^{45}$ and increasing availability of formal and informal mental health services through telemedicine and other alternative venues. ${ }^{46,47}$

The major limitation of this study is the use of a web-based convenience sample, which raises concerns about the potential for selection biases and may limit the generalizability of our findings. For example, if selection into the sample differed by both mental health and life change stress indicators, this could have inflated the association between life change stress and mood. Use of this sample was motivated by the need to quickly develop and deploy the CRISIS questionnaire. CRISIS being used in several studies across the world will allow for the comparison of results across sample types and locations. In addition, we relied on recall for measurement of pre-pandemic mental health, and relied on parent reports for children, which may be less accurate for older children and for internalizing symptoms across ages. ${ }^{48}$ Furthermore, our estimates may have been influenced by sample attrition over time. Strengths of the study include the cross-national sample that enables us to demonstrate overall consistency of findings across the two geographical locations; the investigation of predictors of mental health of children, which is less common in the COVID-19 literature, ${ }^{49,50}$ and the use of sophisticated analytic techniques that allow us to gauge the relative importance of multiple predictors on mood symptoms.

As vaccination rates increase and society returns to "normal," the mental health needs of those with continued psychological distress will need to be addressed. ${ }^{51}$ Longitudinal studies are vital for understanding who is going to continue to struggle post-pandemic. This study suggests that in addition to well-established risk factors for post-disaster mental health, attending to the heterogeneity in the impact of the pandemic on people's daily patterns of interaction and living may provide useful targets for interventions to reduce mood and anxiety symptom levels.

\section{Acknowledgements}

We thank the CRISIS AFAR team for suggestions to incorporate the OxCGRT into our analyses. Aki Nikolaidis is funded by a NARSAD Young Investigator grant and NIMH grant R21 MH118556-01. This study was funded in part by the financial firm Morgan Stanley. Drs. Paksarian and Merikangas are supported by the Intramural Research Program of the National Institute of Mental Health (ZIA MH002953).

\section{References}

1. Kantor, B. N. \& Kantor, J. Mental Health Outcomes and Associations During the COVID-19 Pandemic: A Cross-Sectional Population-Based Study in the United States. Front. Psychiatry 11, 569083 (2020).

2. Fitzpatrick, K. M., Harris, C. \& Drawve, G. Fear of COVID-19 and the mental health consequences in America. Psychol. Trauma 12, S17-S21 (2020).

3. Duan, L. et al. An investigation of mental health status of children and adolescents in china during the outbreak of COVID-19. J. Affect. Disord. 275, 112-118 (2020).

4. Demirjian, N. L. et al. Impacts of the Coronavirus Disease 2019 (COVID-19) pandemic on healthcare workers: A nationwide survey of United States radiologists. Clin. Imaging 68, 218-225 (2020). 
medRxiv preprint doi: https://doi.org/10.1101/2021.08.10.21261860; this version posted August 11, 2021. The copyright holder for this preprint (which was not certified by peer review) is the author/funder, who has granted medRxiv a license to display the preprint in perpetuity. All rights reserved. No reuse allowed without permission.

5. Li, Y., Luan, S., Li, Y. \& Hertwig, R. Changing emotions in the COVID-19 pandemic: A three-wave longitudinal study in the United States and China. (2020).

6. Pierce, M. et al. Mental health before and during the COVID-19 pandemic: a longitudinal probability sample survey of the UK population. Lancet Psychiatry 7, 883-892 (2020).

7. Westrupp, E. et al. Child, parent, and family mental health and functioning in Australia during COVID-19: Comparison to pre-pandemic data. (2020) doi:10.31234/osf.io/ydrm9.

8. Hawes, M. T., Szenczy, A. K., Olino, T. M., Nelson, B. D. \& Klein, D. N. Trajectories of depression, anxiety and pandemic experiences; A longitudinal study of youth in New York during the Spring-Summer of 2020. Psychiatry Res. 298, (2021).

9. Robinson, E. \& Daly, M. Explaining the rise and fall of psychological distress during the COVID-19 crisis in the United States: Longitudinal evidence from the Understanding America Study. Br. J. Health Psychol. (2020) doi:10.1111/bjhp.12493.

10. Pierce, M. et al. Mental health responses to the COVID-19 pandemic: a latent class trajectory analysis using longitudinal UK data. Lancet Psychiatry 8, 610-619 (2021).

11. Goldmann, E. \& Galea, S. Mental health consequences of disasters. Annu. Rev. Public Health 35, 169$183(2014)$.

12. Whalley, M. G. \& Brewin, C. R. Mental health following terrorist attacks. Br. J. Psychiatry 190, 94-96 (2007).

13. Bonanno, G. A., Galea, S., Bucciarelli, A. \& Vlahov, D. What predicts psychological resilience after disaster? The role of demographics, resources, and life stress. J. Consult. Clin. Psychol. 75, 671-682 (2007).

14. Ahorsu, D. K. et al. The Fear of COVID-19 Scale: Development and Initial Validation. International Journal of Mental Health and Addiction (2020) doi:10.1007/s11469-020-00270-8.

15. Pan, K.-Y. et al. The mental health impact of the COVID-19 pandemic on people with and without depressive, anxiety, or obsessive-compulsive disorders: a longitudinal study of three Dutch case-control cohorts. Lancet Psychiatry 8, 121-129 (2021).

16. Fancourt, D., Steptoe, A. \& Bu, F. Trajectories of anxiety and depressive symptoms during enforced 
medRxiv preprint doi: https://doi.org/10.1101/2021.08.10.21261860; this version posted August 11, 2021. The copyright holder for this preprint (which was not certified by peer review) is the author/funder, who has granted medRxiv a license to display the preprint in perpetuity.

All rights reserved. No reuse allowed without permission.

isolation due to COVID-19 in England: a longitudinal observational study. The Lancet Psychiatry 8, 141$149(2021)$.

17. Breslau, J. et al. A longitudinal study of psychological distress in the United States before and during the COVID-19 pandemic. Prev. Med. 143, (2021).

18. Serafini, G. et al. The psychological impact of COVID-19 on the mental health in the general population. QJM (2020) doi:10.1093/qjmed/hcaa201.

19. Kelly, B. D. Quarantine, restrictions and mental health in the COVID-19 pandemic. QJM (2020) doi:10.1093/qjmed/hcaa322.

20. Nikolaidis, A. et al. The Coronavirus Health and Impact Survey (CRISIS) reveals reproducible correlates of pandemic-related mood states across the Atlantic. medRxiv (2020) doi:10.1101/2020.08.24.20181123.

21. Peer, E., Brandimarte, L., Samat, S. \& Acquisti, A. Beyond the Turk: Alternative platforms for crowdsourcing behavioral research. J. Exp. Soc. Psychol. 70, 153-163 (2017).

22. Larsen, R. J. \& Diener, E. Promises and problems with the circumplex model of emotion. (1992).

23. Posner, J., Russell, J. A. \& Peterson, B. S. The circumplex model of affect: An integrative approach to affective neuroscience, cognitive development, and psychopathology. Dev. Psychopathol. 17, 715 (2005).

24. Hale, T. et al. A global panel database of pandemic policies (Oxford COVID-19 Government Response Tracker). Nat Hum Behav 5, 529-538 (2021).

25. Nikolaidis, A. et al. Bagging improves reproducibility of functional parcellation of the human brain. Neuroimage 116678 (2020).

26. Probst, P., Wright, M. N. \& Boulesteix, A. Hyperparameters and tuning strategies for random forest. WIREs Data Mining Knowl Discov 9, 281 (2019).

27. Breiman, L. Random Forests. Mach. Learn. 45, 5-32 (2001).

28. Strobl, C., Boulesteix, A.-L., Zeileis, A. \& Hothorn, T. Bias in random forest variable importance measures: illustrations, sources and a solution. BMC Bioinformatics 8, 25 (2007).

29. Holman, E. A., Thompson, R. R., Garfin, D. R. \& Silver, R. C. The unfolding COVID-19 pandemic: A probability-based, nationally representative study of mental health in the United States. Sci Adv 6, (2020).

30. Wetherall, K. et al. Mental health and well-being during the COVID-19 pandemic: longitudinal analyses of 
medRxiv preprint doi: https://doi.org/10.1101/2021.08.10.21261860; this version posted August 11, 2021. The copyright holder for this preprint (which was not certified by peer review) is the author/funder, who has granted medRxiv a license to display the preprint in perpetuity.

All rights reserved. No reuse allowed without permission.

adults in the UK COVID-19 Mental Health \& Wellbeing study. Br. J. Psychiatry 1-8.

31. Freedy, J., Kilpatrick, D. \& Resnick, H. S. Natural Disasters and Mental Health: Theory, Assessment, and Intervention. Corte Madera, CA 8, 49 (1993).

32. Bromet, E. J. \& Havenaar, J. M. Psychological and perceived health effects of the Chernobyl disaster: a 20-year review. Health Phys. 93, 516-521 (2007).

33. Keller, A. et al. Does the perception that stress affects health matter? The association with health and mortality. Health Psychol. 31, 677-684 (2012).

34. Marroquín, B., Vine, V. \& Morgan, R. Mental health during the COVID-19 pandemic: Effects of stay-athome policies, social distancing behavior, and social resources. Psychiatry Res. 293, 113419 (2020).

35. Williams, S. N., Armitage, C. J., Tampe, T. \& Dienes, K. Public perceptions and experiences of social distancing and social isolation during the COVID-19 pandemic: A UK-based focus group study. doi:10.1101/2020.04.10.20061267.

36. Elbogen, E. B., Lanier, M., Blakey, S. M., Wagner, H. R. \& Tsai, J. Suicidal ideation and thoughts of selfharm during the COVID-19 pandemic: The role of COVID-19-related stress, social isolation, and financial strain. Depress. Anxiety (2021) doi:10.1002/da.23162.

37. Varga, T. V. et al. Loneliness, worries, anxiety, and precautionary behaviours in response to the COVID19 pandemic: a longitudinal analysis of 200,000 Western and Northern Europeans. The Lancet Regional Health - Europe 100020 (2021).

38. Campion, J., Javed, A., Sartorius, N. \& Marmot, M. Addressing the public mental health challenge of COVID-19. Lancet Psychiatry 7, 657-659 (2020).

39. Druss, B. G. Addressing the COVID-19 Pandemic in Populations With Serious Mental IIIness. JAMA Psychiatry 77, 891-892 (2020).

40. Brooks, S. K. et al. The psychological impact of quarantine and how to reduce it: rapid review of the evidence. The Lancet vol. 395 912-920 (2020).

41. Bromet, E. J. \& Litcher-Kelly, L. Psychological Response of Mothers of Young Children to the Three Mile Island and Chernobyl Nuclear Plant Accidents One Decade Later. in Toxic Turmoil: Psychological and Societal Consequences of Ecological Disasters (eds. Havenaar, J. M., Cwikel, J. G. \& Bromet, E. J.) 69- 
medRxiv preprint doi: https://doi.org/10.1101/2021.08.10.21261860; this version posted August 11, 2021. The copyright holder for this preprint (which was not certified by peer review) is the author/funder, who has granted medRxiv a license to display the preprint in perpetuity. All rights reserved. No reuse allowed without permission.

84 (Springer US, 2002).

42. Benfer, E. A. et al. Eviction, Health Inequity, and the Spread of COVID-19: Housing Policy as a Primary Pandemic Mitigation Strategy. J. Urban Health 98, 1-12 (2021).

43. Leddy, A. M., Weiser, S. D., Palar, K. \& Seligman, H. A conceptual model for understanding the rapid COVID-19-related increase in food insecurity and its impact on health and healthcare. The American Journal of Clinical Nutrition vol. 112 1162-1169 (2020).

44. Bäuerle, A. et al. An e-mental health intervention to support burdened people in times of the COVID-19 pandemic: CoPE It. J. Public Health 42, 647-648 (2020).

45. Evans, M. L., Lindauer, M. \& Farrell, M. E. A Pandemic within a Pandemic — Intimate Partner Violence during Covid-19. New England Journal of Medicine vol. 383 2302-2304 (2020).

46. Zhou, X. et al. The Role of Telehealth in Reducing the Mental Health Burden from COVID-19. Telemed. J. E. Health. 26, 377-379 (2020).

47. Salum, G. A. et al. Letter to the editor: Training mental health professionals to provide support in brief telepsychotherapy and telepsychiatry for health workers in the SARS-CoV-2 pandemic. Journal of Psychiatric Research vol. 131 269-270 (2020).

48. Aebi, M. et al. The contribution of parent and youth information to identify mental health disorders or problems in adolescents. Child Adolesc. Psychiatry Ment. Health 11, 23 (2017).

49. Wade, M., Prime, H. \& Browne, D. T. Why we need longitudinal mental health research with children and youth during (and after) the COVID-19 pandemic. Psychiatry research vol. 290113143 (2020).

50. Ravens-Sieberer, U. et al. Impact of the COVID-19 pandemic on quality of life and mental health in children and adolescents in Germany. Eur. Child Adolesc. Psychiatry (2021) doi:10.1007/s00787-02101726-5.

51. Maulik, P. K., Thornicroft, G. \& Saxena, S. Roadmap to strengthen global mental health systems to tackle the impact of the COVID-19 pandemic. Int. J. Ment. Health Syst. 14, 57 (2020). 
Figure 1. May Life Change Stress Subtypes.

\section{A Adult (Self-Report)}

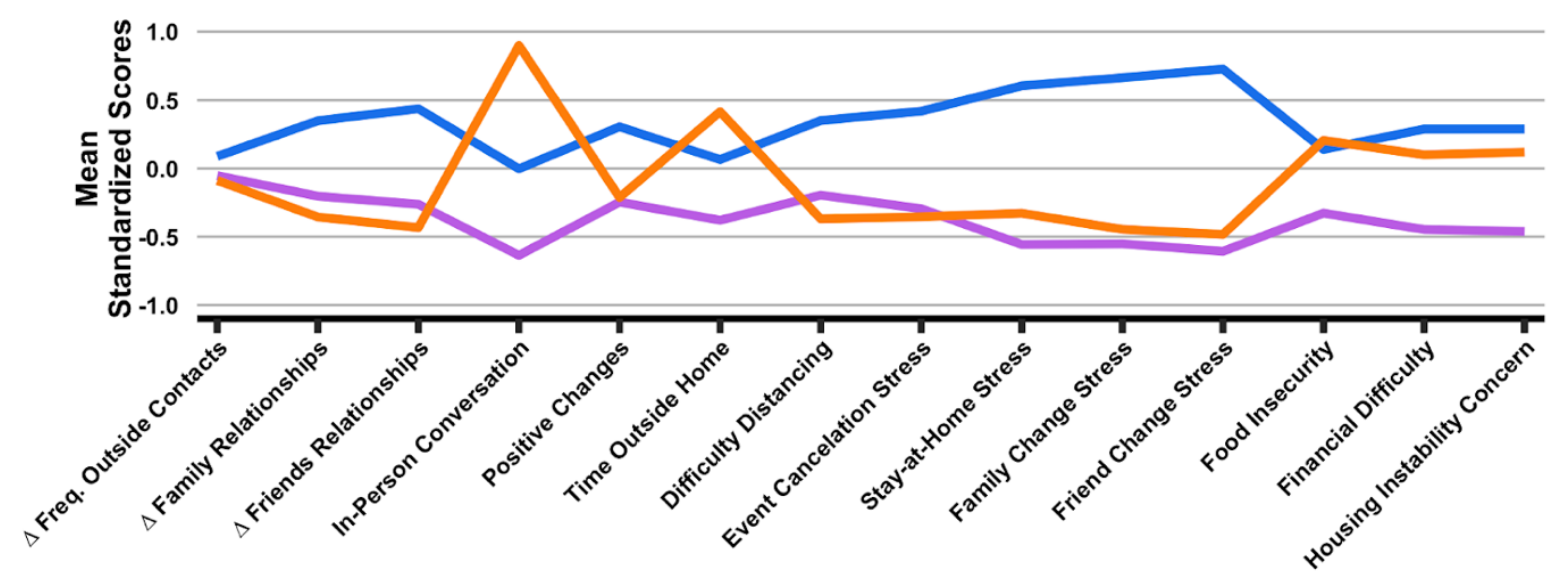

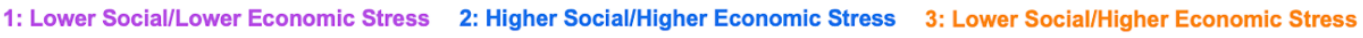

\section{B Child (Parent-Report)}

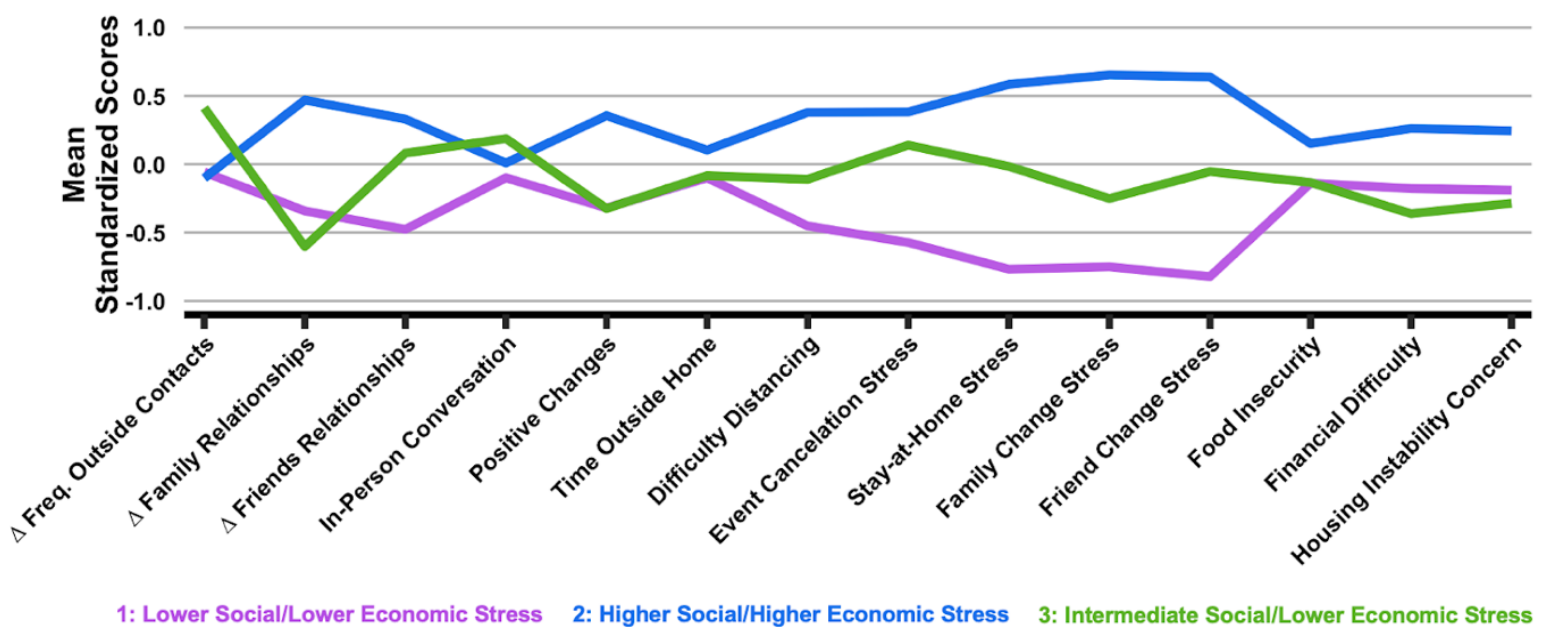

Note: A. Life Change Stress Subtype profiles for adults (top) and children (bottom) in May 2020. Mean normalized profile loadings are displayed on the $y$-axis. $\Delta$ Family Relationships and $\Delta$ Friends Relationships are coded so that higher scores indicate worsening quality of relationships. In-Person Conversation, Positive Changes, and Time Outside Home are coded so that higher scores indicate less conversations, positive changes, and time spent outside. Adult Report: Purple (1): Lower Social/Lower Economic Stress, Blue (2): Higher Social/Higher Economic Stress, Orange (3): Lower Social/Higher Economic Stress. Parent Report: Purple (1): Lower Social/Lower Economic Stress, Blue (2): Higher Social/Higher Economic Stress, Green (3): Intermediate Social/Lower Economic Stress. 
Figure 2: Stability and change in Life Change Stress Subtype across time points with mean mood and COVID Worries scores by group

A

Adult (Self-Report)

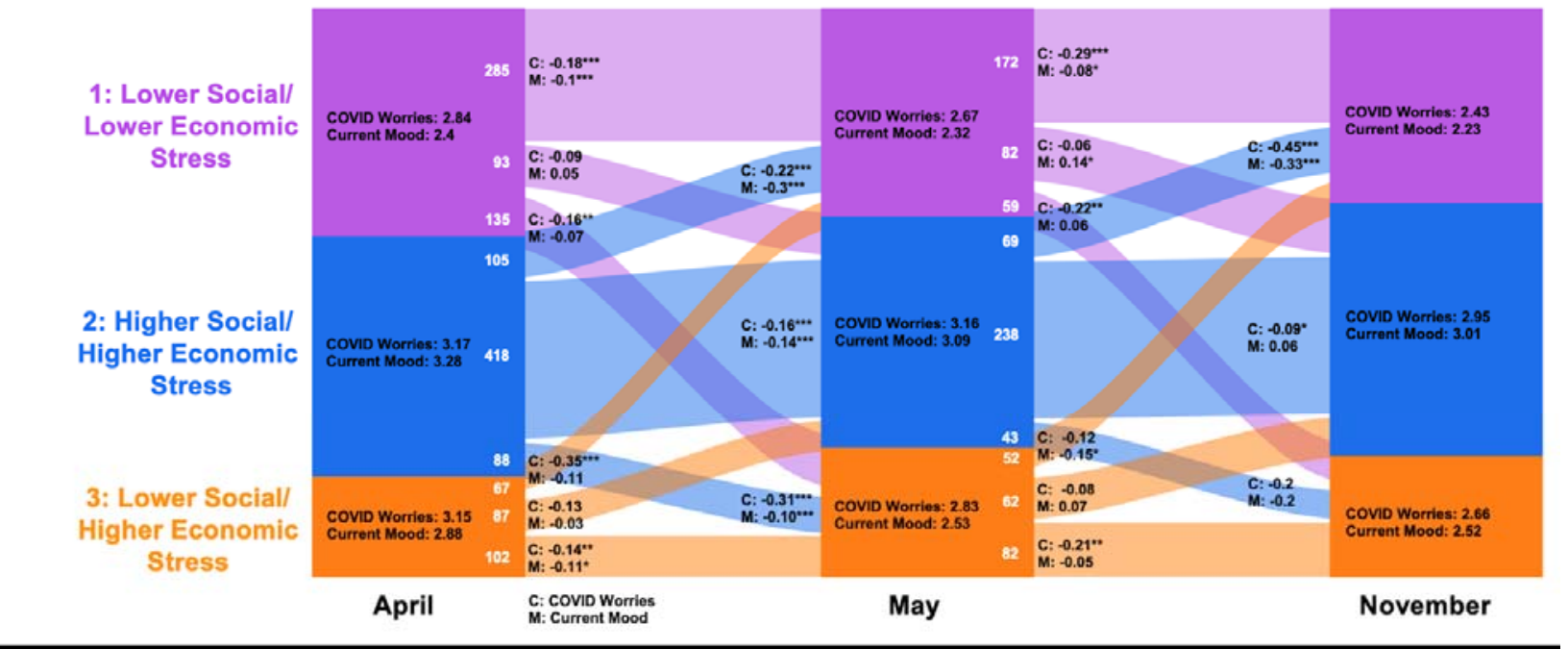

B

\section{Child (Parent-Report)}

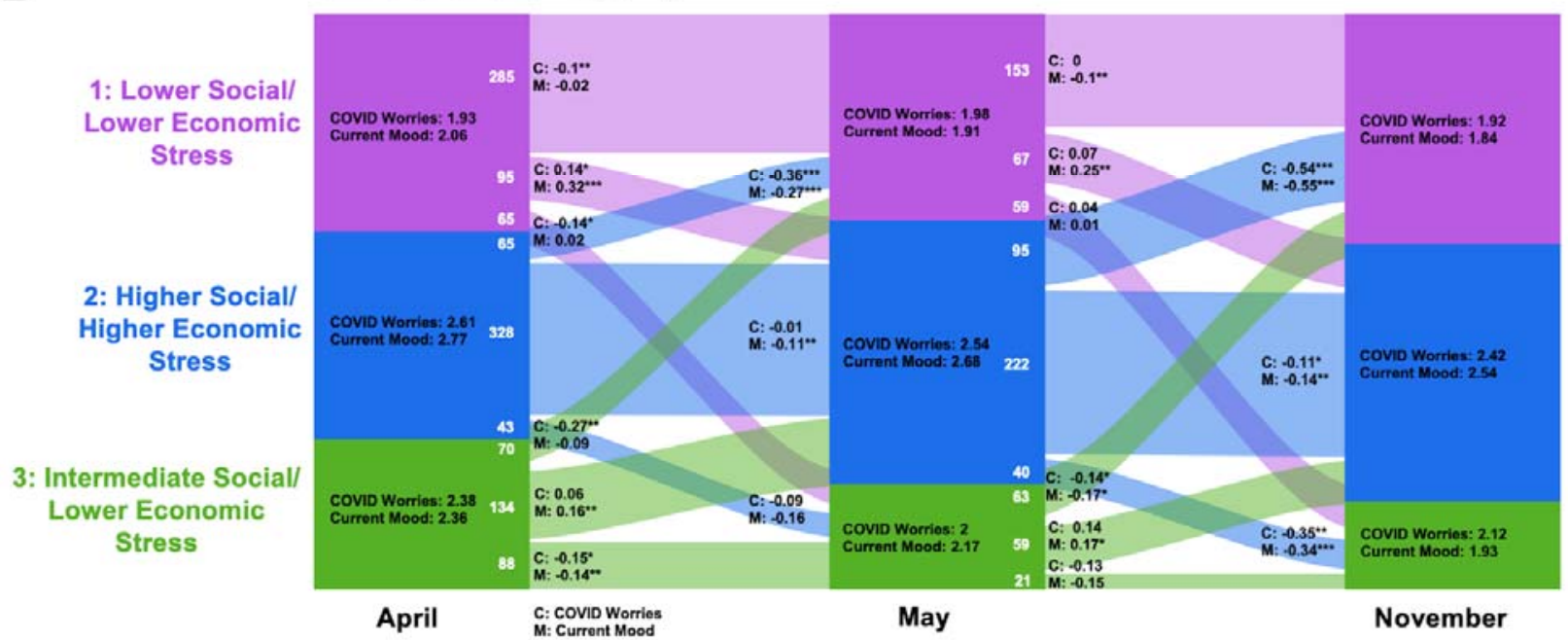

Note: Colored areas correspond to the proportion of participants in each subgroup at each time point. The numbers of individuals moving between Subtypes are given in white, with proportions indicated by the width of the colored paths. Mean COVID Worries and Current Mood scores are represented by Subtype in the center of each column. COVID Worries (C:) and Mood (M:) are represented in the change paths for each change group. T-tests compared the change in the scores between time points for each change group: ${ }^{*}=p<0.05,{ }^{* *}=p<0.01,{ }^{* * *}=p<0.001$. 


\section{Figure 3: Results of conditional random forest models predicting Current Mood in November 2020}
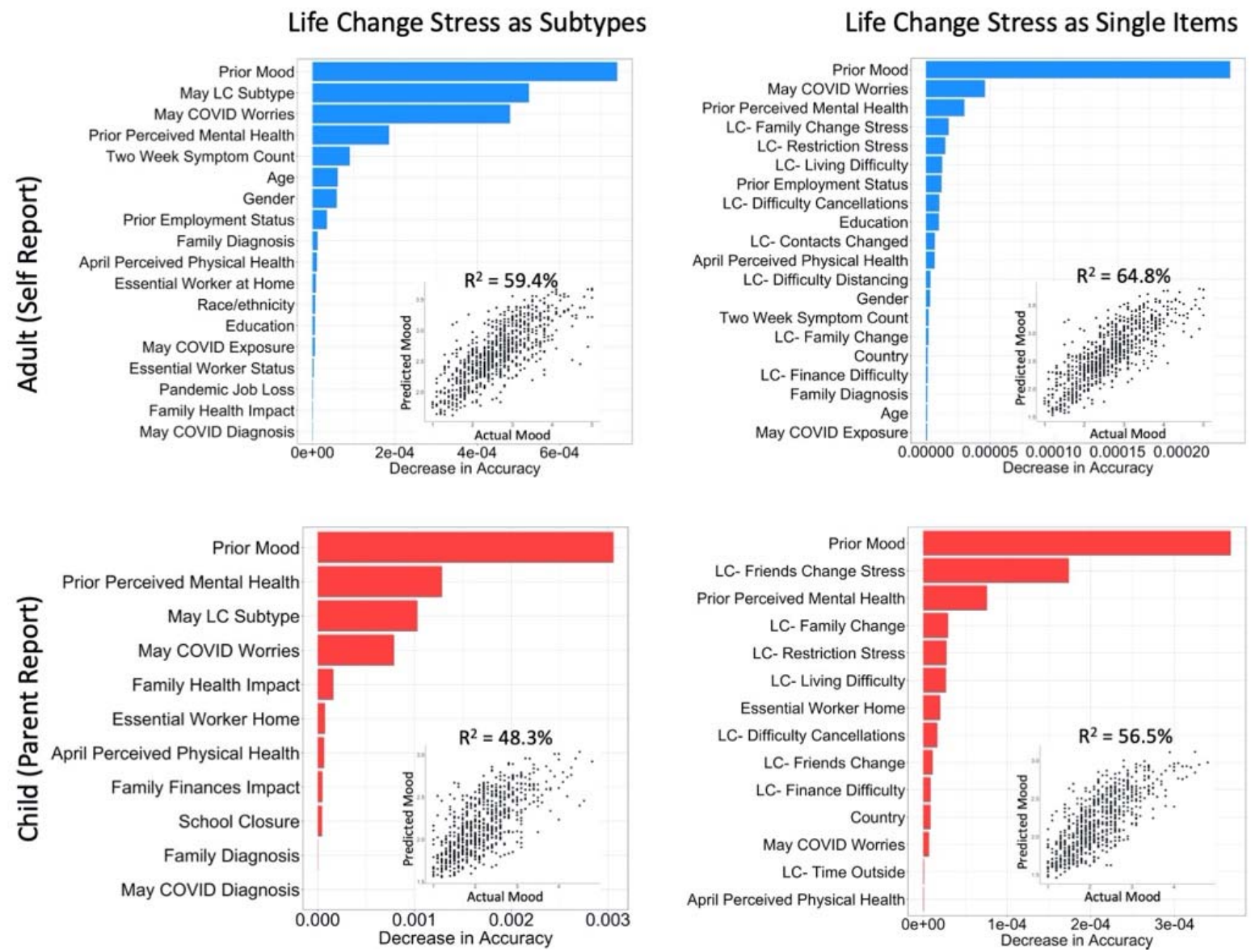

Note: Conditional Random Forest Models in adults (top; $n=827$ ) and children (bottom; $n=750$ ) showing the conditional variable importance of each predictor. Variable importance is calculated based on decreases in accuracy when a variable is removed conditioned on all other variables in a model using balanced bootstrapped partitions of the data to ensure unbiased importance estimates. Only variables with importance values greater than zero are shown. Life change stress was included as data-derived subtypes on the left and as individual indicators on the right. 
Table 1: Sample characteristics with mean Current Mood scores and adjusted associations with Current Mood

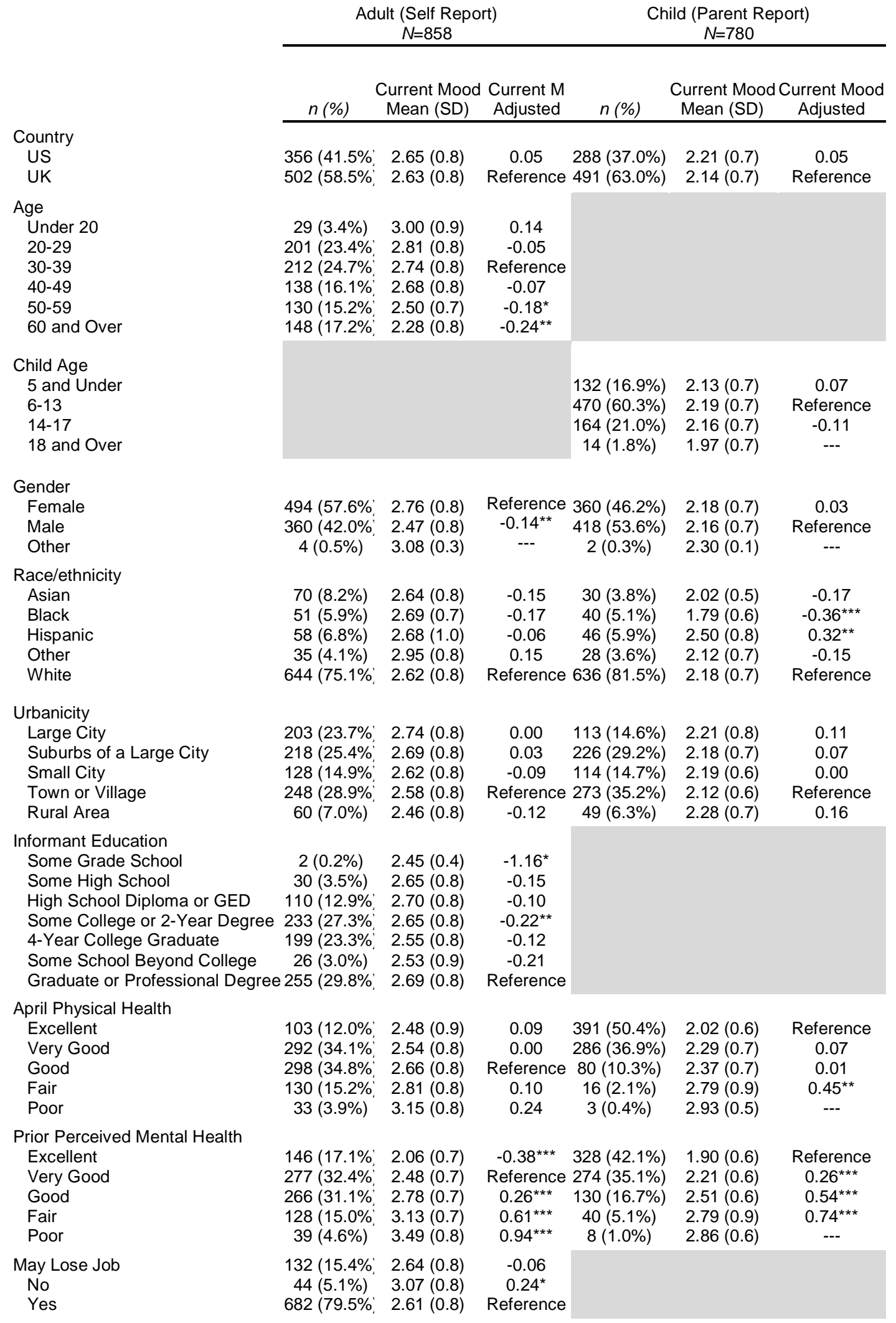


Not Applicable

May Employment Status

Working

Unemployed

Student

Retired, Disabled or Homemaker $182(21.4 \%$
$438(51.6 \%$
$129(15.2 \%$
$100(11.8 \%$
$182(21.4 \%$

$2.61(0.8)$

$2.78(0.7)$

$2.94(0.8)$

$2.44(0.8)$

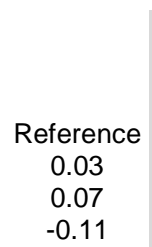

April School Closure

School Did Not Close

School Did Close

Not Applicable

Essential Worker in Family No

Yes

May Health Impact
No

Yes

May Financial Impact

No

Yes

May Exposure

No

Yes, diagnosis positive

Yes, symptoms only

Yes, tested positive

May Infected

Yes, has positive test

Yes, medical diagnosis, no test

Yes, symptoms, no diagnosis

No symptoms or signs

Family Member Dx

No

Yes

2-Week Symptom Count
None
One
Two
Three or More
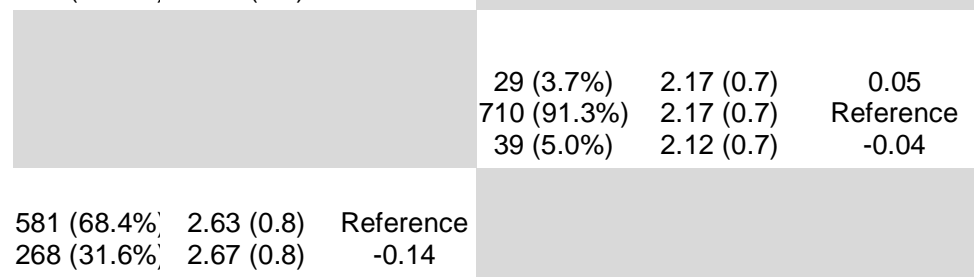

$\begin{array}{ccc}581(68.4 \% & 2.63(0.8) & \text { Reference } \\ 268(31.6 \%, & 2.67(0.8) & -0.14\end{array}$

675 (78.7\%' $2.61(0.8) \quad$ Reference $639(82.0 \%) \quad 2.13(0.7)$

$183(21.3 \%, 2.76(0.8) \quad-0.01 \quad 140(18.0 \%) \quad 2.35(0.8)$

Reference

0.04

$570(66.4 \%, 2.56(0.8)$

$288(33.6 \%, \quad 2.80(0.8)$

Refer
0.11

$0.11209(26.8 \%) \quad 2.34(0.7)$

Reference

$770(89.7 \%, \quad 2.62(0.8)$

Reference $735(94.4 \%) \quad 2.15(0.7)$

$0.12 \quad 10(1.3 \%) \quad 3.13(1.1)$

$0.13 \quad 28(3.6 \%) \quad 2.21(0.6)$

$\begin{array}{lll}-0.12 & 6(0.8 \%) & 2.67(0.7)\end{array}$

$0.12^{*}$

$13(1.5 \%) \quad 3.13(0.9)$

$48(5.6 \%) \quad 2.89(0.9)$

$27(3.1 \%) \quad 2.58(0.9)$

$1(0.1 \%) \quad 1.50(\mathrm{NA})$

$7(0.8 \%) \quad 3.13(0.8)$

$96(11.2 \%) \quad 2.92(0.8)$

$753(87.9 \%, \quad 2.60(0.8)$

--- $\quad 0(0.0 \%)$

$\begin{array}{cc}--- & 2(0.3 \%) \\ 0.16^{*} & 39(5.0 \%)\end{array}$

NA

Reference $737(94.7 \%) \quad 2.16(0.7)$

$798(93.1 \%, \quad 2.63(0.8)$

Reference 728 (93.7\%) $2.15(0.7)$

$\begin{array}{lll}0.15 & 49(6.3 \%) \quad 2.48(0.7)\end{array}$

Reference

$0.45^{*}$

$-0.04$

$---$

$59(7.1 \%) \quad 2.81(0.7)$

$502(58.5 \%, 2.52(0.8)$

$194(22.6 \%, 2.71(0.8)$

$81(9.4 \%) \quad 2.93(0.8)$

$81(9.4 \%) \quad 2.97(0.7)$

Reference $573(73.6 \%) \quad 2.13(0.7)$

$0.11 \quad 156(20.0 \%) \quad 2.24(0.7)$

$0.85 \quad 28(3.6 \%) \quad 2.41(0.9)$

$\begin{array}{lll}0.04 & 22(2.8 \%) & 2.34(0.7)\end{array}$
$---$

$-0.20$

Reference

Reference

$0.22^{*}$

Reference

0.07

0.24

0.11

Note: $\mathrm{N}=858$ adults and 780 children assessed via parent report. Current Mood factor scores range from 1 to 5 . Adjusted associations were estimated via multiple linear regression. Beta values were not estimated for cells with less than ten participants. ${ }^{*}=p<.05,{ }^{* *}=p<.01,{ }^{* * *}=p<.001$. 
Table 2: Mood, COVID Worries, demographic characteristics, and COVID impact indicators across May life change stress subtypes.

Adult (Self Report)

Life Change Stress Subtype

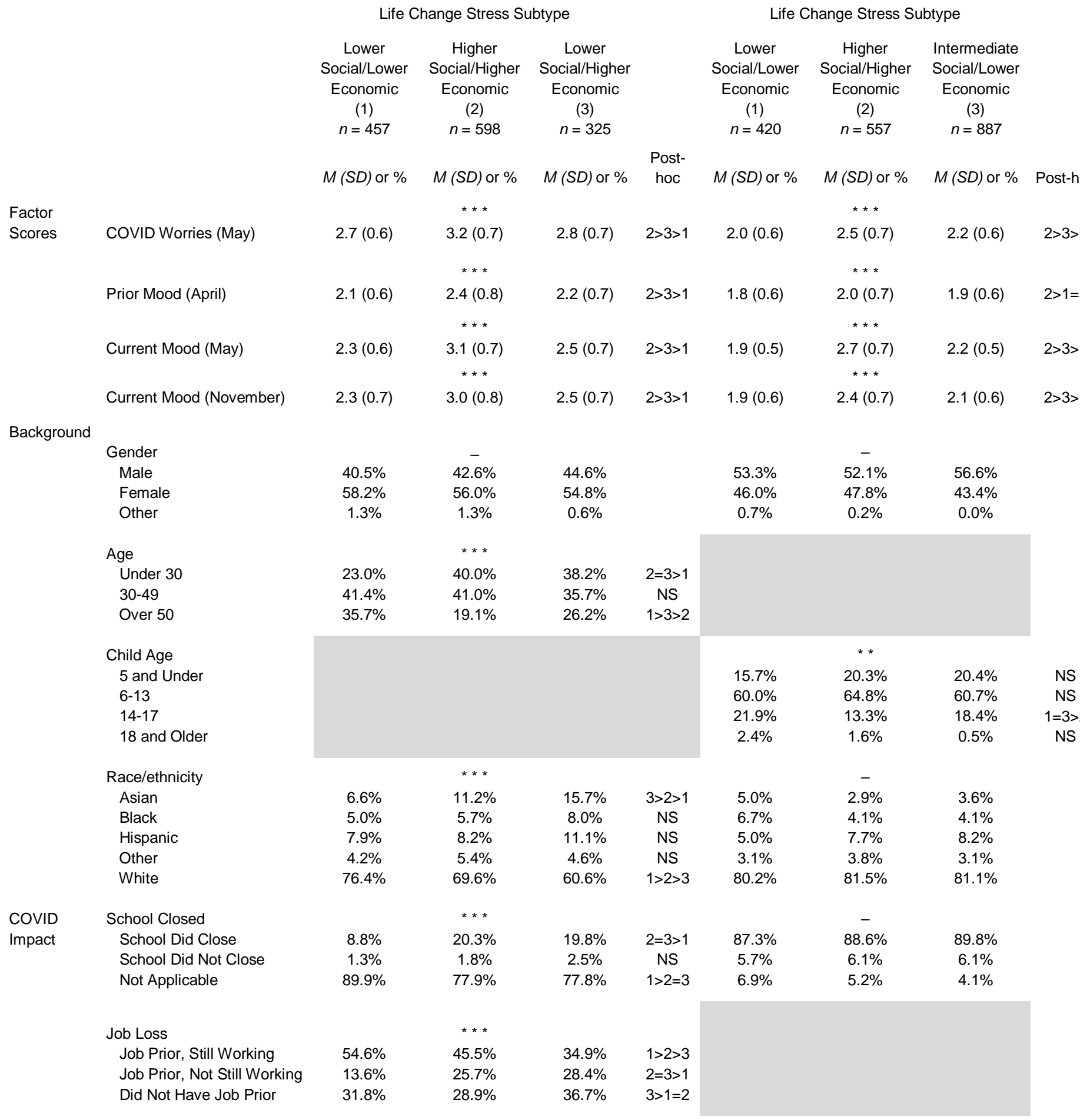

Note. $N=1,380$ adults and $N=1,173$ children assessed via parent report. Chi-square tests and one-way analysis of variance were conducted to test group differences. Variables for prior mood and race were assessed at the April 
medRxiv preprint doi: https://doi.org/10.1101/2021.08.10.21261860; this version posted August 11, 2021. The copyright holder for this preprint (which was not certified by peer review) is the author/funder, who has granted medRxiv a license to display the preprint in perpetuity.

All rights reserved. No reuse allowed without permission.

timepoint and current mood was assessed at both the May and November timepoints. All other variables were assessed at the May timepoint. 